\title{
REPORT OF THE WORKSHOP, "PROSPECTS FOR TEMPORAL EXTENSION OF THE RADIOCARBON CALIBRATION”, 19 MAY 1991
}

Approximately 50 colleagues took part in a lively and informative informal workshop. The aim was to review the following questions: What are the prospects for extending absolutely dated tree-ring chronologies in at least two parts of the world? How might this be done? Might materials other than tree rings be used, or is their dating too uncertain? What implications does the recent work using $\mathrm{U} / \mathrm{Th}$ ratios have for this process?

Two presentations gave a basis for optimism on the prospects for an affirmative answer to the first question. D. A. Graybill, H. Michael and D. J. Donahue reported on some bristlecone pine wood that either predates or has only slight overlap with the existing long bristlecone pine chronologies. This might extend the chronology drawn from one species at a single site to more than 10,000 calendar years. M. Barbetti discussed the increasingly good prospects of a Tasmanian chronology based on subfossil logs eventually extending through the Holocene, and perhaps longer. Naturally, the ensuing discussion also touched upon Becker's extension of the south German chronology using pines.

I. Hadjas discussed the use of laminated lake sediments to extend the calibration, as did a group including T. Goslar, M. F. Pazdur, E. Bard and M. Arnold. It became clear that much progress is being made with the difficult problem of establishing absolute chronology with these sediments, although at the time of the workshop, extensions to the calibration based on lakes studied by these groups would not have agreed with one another. F. Yiou and G. Raisbeck introduced to the discussion the use of ${ }^{10} \mathrm{Be}$ for establishing chronologies for the past 10,000 years, and R. S. Sternberg dealt with the relation of the geomagnetic dipole moment to ${ }^{14} \mathrm{C}$, and the constraints paleomagnetic data could put on ${ }^{14} \mathrm{C}$ variations.

We were fortunate to have an impromptu tutorial on the $\mathrm{U} / \mathrm{Th}$ ratio method from E. Bard, who also gave a summary of his recent results. This was complemented by a report from G. Burr, L. Edwards, D. J. Donahue and E. Druffel on preliminary measurements of ${ }^{14} \mathrm{C}$ and $\mathrm{U} / \mathrm{Th}$ dates in coral. It became clear that $\mathrm{U} / \mathrm{Th}$ dates from coral will provide an invaluable method of constraining ${ }^{14} \mathrm{C}$ dates for periods before $9000 \mathrm{BC}$ for which absolute calibration is not yet available, as well as providing the basis for geophysical insights.

Malcolm K. Hughes and Steven W. Leavitt Laboratory of Tree-Ring Research, The University of Arizona, Tucson, Arizona 85721 USA 